\title{
COMMENTARIES
}

\section{Racism Is Real. Racism Is Complicated. Racism Is Real Complicated.}

Stephen A. Wilson, MD, MPH

(Fam Med. 2019;51(1):8-10.)

doi: 10.22454/FamMed.2019.413518

$\mathbf{R}$ acism is not a scheme to blame white people for everything, make them feel guilty, or appropriate or reappropriate wealth. Racism is the belief or notion that race is the primary determinant of human traits and capacities and that these racial differences result in inherent superiority or inferiority. ${ }^{1}$ This is more detrimental than stereotyping, which is an overgeneralized, oversimplified image, idea, belief, or judgement about a group that is then applied uncritically as true to each individual in the group. This issue of Family Medicine explores race and racism in medical education. $\mathrm{Al}$ though race is hard to define and often comes down to the "eye test," this clumsy and unreliable way of separating human beings into groups is a marker associated with health outcomes, unequal treatment, and reflexive thinking. It is also an opportunity to hope and work for change.

Racism matters medically because its effects on thinking and behavior have been associated with racial disparities in disease and outcomes. Compared to white people, black people die younger and are afflicted disproportionately with diabetes, cardiovascular heart disease, hypertension, and obesity. ${ }^{2}$ Infant mortality for black babies is nearly double that for non-Hispanic white, and Hispanic babies. ${ }^{3}$ Pregnancy mortality rates for black women is more the three times that of white women, and more than twice that of women of other races and ethnicities. ${ }^{4}$ Being black negatively impacts the beginning, end, and in-between of the life expectancy arc.
Racism diminishes, demoralizes, and dehumanizes us all. It is part of the multifactorial etiology of health inequity and health disparity, usually working below the surface and affecting us in surprising and unexpected ways. The form of racism that slithers quietly below the surface decreasing our ability to love our neighbors as ourselves can be referred to as implicit social cognition, or implicit bias.

Implicit bias is the unconscious attribution of particular qualities to a member of a certain social group..$^{5}$ It is influenced by experiences and can affect expectations, performance, and judgement. It is relatively automatic, arising from past experiences that are not available for recall, self-report, or introspection. We all do it as part of our survival instinct. It is a type of System 1 Thinking, which is fast, automatic, frequent, emotional, stereotypic, and unconscious, as opposed to System 2 Thinking, which is slower, effortful, less frequent, logical, calculating, and conscious. ${ }^{6}$ Since it is driven by experiences and exposures that we usually do not remember, either type of thinking can aid escape from or moving closer to danger; either can move us closer to or further from racism.

The generalized expectations we have prior to interacting with a person stem from implicit biases. Some common examples of such expectations include thoughts like "white people are privileged"; "black people need extra help"; "underrepresented minorities* (URM) are bad test

From the University of Pittsburgh Department of Family Medicine, Pittsburgh, PA. 
takers"; "Asians are smart"; "Indians are Hindu"; "He's athletic, for a white guy"; and "He speaks well, for being black." Expectations and thinking like this are more insidious than we realize. Take the parent of an interracial child who is initially taken aback when the mixedrace son starts dating a woman who is not racially concordant with either parent or himself. The unconscious expectation was that the child would be with someone who was racially familiar. This is no-fault, unconscious bias. Once exposed and brought to awareness, the parent's conscious actions or reactions became her responsibility, her decision, her intentional response. The desire to be more equitable in such conscious responses to the point where habitual, unwarranted responses fade, is a source of hope for reconciliation.

These are all parts of the rationale to this issue of Family Medicine being devoted to racism and implicit bias. The more we consciously think about the things we normally do without thinking, the more we can become better health care providers and medical educators who can effectively shepherd a system toward greater health equity.

How physicians are educated contributes to the mental inputs that affect implicit bias formation. A basic influencer is exposure to a broad variety of patients during training. Joseph Hobbs, MD, and colleagues found that regardless of their race and sex, medical students in family medicine clerkships experienced similar types of patients (age, sex, disease, race). ${ }^{7}$ This similarity included an equally relative lack of seeing pregnant patients during their clerkship experiences.

What do learners think and feel about moving the unconscious into the conscious? Syeachia Dennis, MD, et al found that generally, residents did not mind exploring racism presented as a social determinant of health in a curriculum that was linked to 15 Family Medicine Milestones: eight in professionalism, three in systems-based practice, three in communication, and one in patient care. ${ }^{8}$ While residents did report some discomfort and concerns, there were more reports of increased awareness and self-awareness. ${ }^{8}$

Intervening more insistently and assertively through an "antioppression curriculum," Diana $\mathrm{Wu}, \mathrm{MD}$, and colleagues found that a workshop with multiple teaching approaches successfully taught participants to engage in allyship_- "an active, consistent, and arduous practice of unlearning and reevaluating, in which a person of privilege seeks to operate in solidarity with a marginalized group or people."9 Their paired pre- and postassessments allowed each person's experiences to be compared individually instead of through simple group mean comparisons. Workshop participants gained knowledge, confidence, and skills in allyship. ${ }^{10}$

As both Jessicah Guh, MD, and Maria Harsha Wusu, MD, demonstrate in their separate articles, intentional actions can result in increased presence of URM as family medicine residents and faculty. ${ }^{10,11}$ Both employed a distinct multifaceted approach that should be viewed as a singular intervention. Whether by revising recruiting approach and increasing standardization of the interview process to decrease unintended bias, ${ }^{11}$ revising a mission statement, getting outside review of the recruitment process, adding education on the impact of race on health, or moving from process-oriented to goal-oriented ranking, ${ }^{10}$ both included some form of evaluation and tracking of their efforts as part of their respective intervention. This is important as it encourages and allows iterative process improvement.

If each family medicine residency program adopted some version of these interventions, the results would be improvements in work environments and recruiting processes, with only some minor reshuffling of URMs across programs, and yet general diversification would still be lacking. Why? Because there are just not enough of us to go around. Approximately $13 \%$ of the US population is black and about $6.5 \%$ of medical students are black. ${ }^{12}$ People of Hispanic ethnicity represent about $17 \%$ of the US population and about $7.5 \%$ of US medical students. ${ }^{13}$ Since a person can be Hispanic and black, some are double-counted. Although more URM medical students go into family medicine ( $7.5 \%$ of black, $9 \%$ of Hispanic) than other specialties, ${ }^{13}$ this still does not reflect the general population. Even if it did, it would not reflect diversity-forward photographs of residency and conference brochures, which are really meant to reflect a spirit of welcomeness, openness, and inclusion, and not an actual demographic reality.

The relatively small number of URM in medicine resulted in some of the studies necessarily combining various people types. ${ }^{7,10}$ For analysis, Hobbs et al divided their groups into white and nonwhite, which included black, Hispanic, Asian, and other. ${ }^{7}$ Guh et al used the typical term "URM" then added "persons of color" (POC [all not non-Hispanic White]) and 
modified URM (POC minus Chinese, Korean, and Indian) to describe and execute various aspects of the study. ${ }^{10}$ The need to lump to generate collective impact is a reminder of the underrepresentation; overaggregation can run the risk of creating a false narrative of "them" versus "us." However, breaking down data among smaller subpopulations can help identify inequities that may be masked by combining subpopulations.

URM may experience things that disappoint and even distress us, ${ }^{14}$ but these do not need to define us..$^{15}$ People may have little input on how someone initially treats them, but we have control over our response and how we treat them and others.

Racism is real. This issue of Family Medicine reminds us it really affects patients and physicians (experiences, outcomes, and feelings), and presents scholarship that prompts reflection and offers approaches to mitigate and diminish its presence and impact. Some day, racism could be like chickenpox: it used to be a surprise to meet an adult who had not experienced it; now it is oddity to one who has.

The purpose of medical education is to improve patient care and outcomes. Part of that process includes enhancing and fostering selfreflection, self-awareness, other-awareness, and actions that enhance health equity. It is in the action phase that we move from knowing about our neighbor to loving our neighbor as ourselves.

\section{Footnote:}

* "Underrepresented Minorities" per the American Association of Medical Colleges comprises blacks, Mexican Americans, Native Americans (that is, American Indians, Alaska Natives, and Native Hawaiians), and mainland Puerto Ricans.

CORRESPONDENCE: Address correspondence to Stephen Wilson, MD, MPH, University of Pittsburgh Department of Family Medicine, 4420 Bayard St, Suite 520, Pittsburgh, PA 15260. wilsons2@upmc.edu.

\section{References}

1. Racism. Merriam-Webster Dictionary. 2018. https://www. merriam-webster.com/dictionary/racism. Accessed November 6, 2018.

2. Mays VM, Cochran SD, Barnes NW. Race, race-based discrimination, and health outcomes among African Americans. Annu Rev Psychol. 2007;58(1):201-225.

3. MacDorman MF, Mathews TJ. QuickStasa: infant mortality rates, by race and hispanic ethnicity of mother-United States, 2000, 2005, and 2010. MMWR. 2014;63(01):25.

4. Centers for Disease Control and Prevention. Pregnancy Mortality Surveillance System. Trends in Pregnancy-Related Mortality in the United States: 1987-2014. https://www.cdc. gov/reproductivehealth/maternalinfanthealth/pregnancymortality-surveillance-system.htm. Accessed November 6, 2018.

5. Greenwald AG, Banaji MR. Implicit social cognition: attitudes, self-esteem, and stereotypes. Psychol Rev. 1995;102(1):4-27.

6. Kahneman D. Thinking, Fast and Slow. New York: Farrar, Straus, and Giroux; 2011.

7. Hobbs J, Kriegel DL, Saicier A, Hodo DM, Looney SW. Student race and gender and patient encounters in a family medicine clerkship. Fam Med. 2019;51(1):14-21.

8. Dennis SN, Gold RS, Wen FK. Learner reactions to activities exploring racism as a social determinant of health. Fam Med. 2019;51(1):41-47.

9. Wu D, Saint-Hilaire L, Pineda A, et al. The efficacy of an antioppression curriculum for health professionals. Fam Med. 2019;51(1):22-30.

10. Guh J, Harris CR, Martinez P, Chen FM, Gianutsos LP Antiracism in residency: a multimethod intervention to increase racial diversity in a community-based residency program. Fam Med. 2019;51(1):37-40.

11. Wusu MH, Tepperberg S, Weinberg JM, Saper RB. Matching our mission: a strategic plan to create a diverse family medicine residency. Fam Med. 2019;51(1):31-36.

12. Wilson SA. Diverse Diversity. Fam Med. 2017;49(10):821-822.

13. Deville C, Huang W-T, Burgos R, Chapman CH, Both S, Thomas CR. Diversity in graduate medical education in the United States by race, ethnicity, and sex. JAMA Intern Med. 2012. 2015;175(10):1706-1708.

14. McKinney-Whitson V. I Guess the MD on my white coat is invisible today. Fam Med. 2019;51(1):57.

15. Frazier W. I'm not here to judge. Fam Med. 2019;51(1):55-56. 